\title{
Experimental investigation of wax deposition from waxy oil mixtures
}

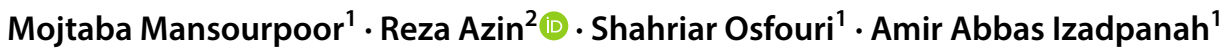

Received: 13 May 2018 / Accepted: 1 May 2019 / Published online: 14 May 2019

(c) The Author(s) 2019

\begin{abstract}
Wax deposition is a common problem in oil pipelines and production systems. In this study, impact of water cut, mixing rate, chemical inhibitor, and time on wax deposition were investigated in a cold finger setup. Effect of different chemical inhibitors on wax appearance temperature (WAT) was studied using viscometry and differential scanning calorimetry techniques. Results suggested that WAT reduced with increasing inhibitor concentration, with $800 \mathrm{ppm}$ being the optimum. Also, chloroform-toluene-ethylene vinyl acetate (EVA) mixture with 30, 30, and $40 \mathrm{wt} \%$ had the highest performance and reduced the WAT to $16.7^{\circ} \mathrm{C}$. Mixtures of toluene-EVA with acetone, p-xylene, and disulfide oil (DSO), followed next. Moreover, deposition decreased with increasing temperature difference between oil and pipe at constant cold surface temperature and increased upon increasing temperature difference at constant oil temperature. Wax deposition in two-phase system was lower than in single-phase system, but increased by increasing water cut. EVA-toluene, $2 \mathrm{wt} \%$ DSO, $2 \mathrm{wt} \%$ acetone, and $2 \mathrm{wt} \%$ p-xylene mixtures reduced the deposition to 23.33, 21.71, 32.14, and 12.5\%, but addition of $2 \mathrm{wt} \%$ of EVA-DSO-acetone mixture reduced deposition to $35.74 \%$. At similar operating conditions, flow turbulence has greater impact on reducing wax deposition, and its effect is enhanced using a proper inhibitor.
\end{abstract}

Keywords Wax deposition $\cdot$ Cold finger $\cdot$ Viscometry $\cdot$ Deposition thickness $\cdot$ WAT

\section{Introduction}

The transportation of oil and condensate through a pipeline has always been challenging due to huge problems such as wax deposition. Wax deposition is considered as the deposition of paraffinic components due to their low solubility in crude oil and condensates under normal conditions [27]. Solubility of paraffinic components at reservoir conditions is high and this material dissolved in the oil mixture completely [24]. When crude oil produced from the reservoir is transported through pipeline, its temperature and pressure drops which leads to reduction in paraffinic solubility. Wax is formed when the cold surface temperature is less than wax appearance temperature (WAT) and there is a temperature

Reza Azin

reza.azin@pgu.ac.ir

1 Chemical Engineering Department, Faculty of Petroleum, Gas and Petrochemical Engineering, Persian Gulf University, Bushehr, Iran

2 Petroleum Engineering Department, Faculty of Petroleum, Gas and Petrochemical Engineering, Persian Gulf University, Bushehr, Iran difference between crude oil and the cold surface. With reducing the solubility of paraffinic components, these components are separated from oil and deposit on the pipe wall and process equipment.Wax deposition in pipelines causes serious problems including increase of oil viscosity, increasing pumping cost, reducing the pipe diameter and sometimes blocking it, temporarily shut down, increasing yield stress, reducing production and also increasing the cost of repairs [24]. Solid deposition in the well can lead to formation damage, reducing permeability, and also change in fluid rheology due to phase separation [34]. Wax removal and preventive methods totally fall into five groups including mechanical, chemical inhibitors, thermal, thermo-chemical and biological methods [31]. Mechanical methods include pigging and scraping are the common removal methods. Thermal preventive and removal methods of wax deposition include hot oil and water injection methods that are too costly and applicable only when the pipeline length is short. Chemical wax inhibitors commonly fall into four main groups including solvents, crystal modifiers, dispersants and surfactants. Crystal modifiers such as ethylene vinyl acetate (EVA) and polyethylene butane prevent the growth of wax crystals by improving the rheological properties of crude oils and 
condensates [25]. Dispersants and surfactants disperse precipitated wax crystals and prevent their accumulation [5].

Different mechanisms have been suggested for wax deposition including molecular diffusion, shear stress, Brownian diffusion and gravity settling [24]. Results of different studies indicate that molecular diffusion has been considered as dominant mechanism in the wax deposition process $[3,4,9$, $17,24,28]$ and shear stress is considerable only when the oil temperature is much lower than WAT and wax concentration in oil is high [4]. Lu et al. [18] reported that molecular diffusion and gelation are the dominant mechanisms of wax deposition. Wax deposition is a function of various factors including flow rate, oil and surface temperature, composition, thermal history, pressure, etc. [23]. Additionally, the amount of wax deposition is influenced by the paraffins concentration, light components and solvents. For preventing and removal of wax deposition it is necessary to study the flow conditions and the effective factors. Various experimental methods such as flow loop, cold finger and rotating cylinder are used to study the wax deposition phenomenon. Design of cold finger apparatus is very simple and it is capable of investigating paraffin deposition at atmospheric conditions. Various experimental studies have been performed in cold finger and flow-loop apparatuses to studies wax deposition at different thermal gradient conditions.

Investigations of Creek et al. [7] in flow loop at constant oil temperature revealed that thermodynamic forces were increased with decreasing cold surface temperature, and was leading to increasing wax deposition. Studies of Jennings and Weispfennig [12] which were carried out in cold finger setup showed that wax deposition increased with increasing the temperature gradient between crude oil and cold surface. Huang et al. [10] observed that wax deposition is not dependent on the temperature difference while solubility curve has a considerable effect on the deposition phenomenon. Theyab and Diaz [26] surveyed the effects of temperature difference, spiral flow, and flow rate under single-phase flow in a flow-loop apparatus and suggested that wax deposition was decreased with increasing cold surface temperature. Also, they reported that simultaneous use of the inhibitor and spiral flow reduced a wax deposition significantly. Using a flow loop at laminar flow regime, Lashkarbolooki et al. [17] found that deposition thickness increases with increasing temperature gradient at both constant oil temperature and constant cold surface temperature which it is somewhat unreasonable. They revealed that temperature difference has much more important effect on the deposition mass than the oil or cold surface temperature alone. Kelechukwu et al. [14] investigated the effects of different factors on the deposit mass and observed that deposition thickness was decreased with increasing flow rate and temperature gradient, while it was increased with time, reached a maximum value and gradually tails off.
A few studies showed that wax deposition in two-phase flow decreases with increasing water cut $[6,32]$. Using a flow loop, Lu et al. [18] conducted experimental studies on the effects of water cut and flow rate on wax deposition and reported that wax thickness was increased with decreasing flow rate and increasing the water cut. They reported that shear stresses were decreased with decreasing flow rate and therefore, wax deposition was increased. Gao [8] used a flow loop and performed wax deposition experiments with different water cuts and observed that wax deposition in the water-free oil system was lower than that in oil-water system and increased with increasing water cuts. Similar experiments were carried out by Panacharoensawad and Sarica [21] showed that water cuts in two-phase flow did not have a direct impact on wax deposition and mainly have a direct impact on shear stress and heat transfer which have a strong impact on deposition thickness. Using cold finger apparatus, Kasumu and Mehrotra [13] studied the effect of water cut and deposition time on wax deposition and reported that the amount of water cuts does not directly affect the amount of deposition. They also found that more than half of wax deposition was formed in the first $30 \mathrm{~s}$.

Different studies reported that increasing flow rates leads to decreasing wax deposition [1, 3, 7, 24, 30]. Matzain [20] investigated the effect of flow rate on wax deposition in a turbulent flow and reported that deposition in a turbulent flow is lower than one in the laminar flow and decreased by increasing the flow rate. Kasumu and Mehrotra [13] reported that deposit mass was decreased with increasing the agitation speed. Brown et al. [3] investigated the effect of shear stress on wax deposition in flow-loop apparatus and observed that the amount of trapped oil in the deposit layer was decreased with increasing shear stress. As consequence, the amount of deposition was decreased and deposit layer becomes harder. Lee-Tuffnell performed studies on changes of wax deposition with shear stress variation within the coaxial shear cell and found that the shear stress reduces wax deposition [12]. Using a cold finger, Jennings and Weispfennig [12] found that paraffin deposition decreased with increasing the shear stress and increasing the temperature gradient between oil sample and the cold surface.

Use of chemical inhibitors is one of the most effective ways for wax prevention. Kudaibergenov et al. [15] proposed a new polyampholyte and showed that the amount of wax crystals is reduced significantly with addition of the new pour point depressant (PPD) and size of the aggregates becomes much smaller than that after heat treatment. Lashkarbolooki et al. [16] studied the influence of combination of EVA with different solvents and observed that the wax deposition reduced to minimum amount by $800 \mathrm{ppm}$ of EVA + asphaltene + p-xylene with $50,25,25 \mathrm{wt} \%$, respectively. Ansaroudi et al. [11] by using a flow-loop setup and scanning electron microscopy (SEM) found that crystals of wax depositions are plate-like 
in the absence of EVA polymer and changed to spherulites with addition of small amount of polymer. So more crystals with smaller size can be produced and they formed weak networks. Ridzuan et al. [22] used different chemical inhibitors and EVA was suggested as the most effective inhibitor. They reported that solubility of paraffin crystals can be significantly controlled by the type of functional group of chemical inhibitor. Wei [29] reviewed advances on polymeric compounds and expressed that efficiency of crystal modifiers is strongly dependent on the capacity of polymer to co-crystallize with wax. Also, this author reports that combining of wax crystal modifiers with solvents could improve inhibition efficiency. Mansourpoor et al. [19] investigated the influence of disulfide oil (DSO), EVA, $\mathrm{SiO}_{2}$ and clay nanoparticles on rheological properties of waxy oils. They reported that waxy oil properties such as gel point, pour point, viscosity, and yield stress decreased upon addition of these inhibitors. In addition, they found that increasing $\mathrm{SiO}_{2}$ and clay nanoparticles up to 0.2 $\mathrm{wt} \%$ in nanohybrid PPD (NPPD) improved the rheological properties of oil samples.

However, there are major discrepancies between previous studies. For example, in case of effect of water cut on wax deposition, Kasumu and Mehrotra [13] and Panacharoensawad and Sarica [21] reported that the amount of water cuts does not directly affect the amount of deposition while $\mathrm{Lu}$ et al. [18] stated that deposition mass increased with increasing water cut. Therefore, due to increasing the amount of water produced along oil production over time, it is required to investigate the effect of this parameter on the wax deposition accurately. Also, disposal of DSO as a by-product of gas refineries leads to environmental pollution and waste of capital. Effect of DSO on the WAT and amount of wax deposition was not studied until now; therefore, this parameter was investigated in this paper. To investigate the effect of EVA PPD on wax prevention performance, various experiments with different mixtures of EVA were carried out on one of Iranian crude oil. Using a viscometer, 12 oil-solvent mixtures were employed to investigate the effect of these PPDs on WAT. Different solvents including p-xylene, acetone, toluene, chloroform, methanol, methyl-diethanolamine (MDEA), and DSO in various ratios are mixed with EVA and crude oils. Also, the effect of water cut, deposition time, stirring speed, temperature difference, and chemical inhibitors on amount of paraffin deposition investigates by using cold finger setup.

\section{Materials and methods}

\section{Materials}

In this study, crude oil with 49.9 API gravity and kerosene were supplied from the Iranian oil and gas fields.
Using viscometry (Anton Paar SVM 3000) and differential scanning calorimetry (DSC) techniques (METTLER TOLEDO DSC823e), the WAT of this crude oil was measured around 25.5 and $24^{\circ} \mathrm{C}$, respectively. DSO with 1.011 specific gravity, 115.9 molecular weight and $0.52 \mathrm{mPa} . \mathrm{s}$ viscosity was supplied by South Pars gas refineries. An EVA copolymer with $28 \mathrm{wt} \%$ vinyl acetate which produced by Lotte Chemical Corporation and solid wax paraffin with $0.5 \%$ oil and a melting temperature of $63{ }^{\circ} \mathrm{C}$ were purchased from the market. Methanol, acetone, chloroform, p-xylene, and toluene with a purity of more than $99.5 \%$ were supplied from Merck. MDEA with minimum 99.0\% purity and maximum $0.5 \mathrm{wt} \%$ water content was purchased from amine and plasticizers Ltd. Co.

\section{Methods}

\section{Cold finger apparatus}

Cold finger and flow-loop testing are common laboratory methodologies used to investigate wax deposition phenomenon. In a cold finger test, hot oil rotates around a cold surface, causing a temperature gradient and concentration gradient, thus providing the driving force required for paraffin deposition. A cold finger apparatus was designed and assembled to study the effect of temperature gradient between oil and a cold surface, stirring speed, water cut, deposition time, and chemical inhibitors on wax deposition. Figure 1 shows schematic of laboratory cold finger setup. A cold finger apparatus consists of two hot and cold circulating water baths with a temperature control capability to maintain temperatures of both the oil and the cold surface. The setup also contains a magnetic stirrer with an adjustable rotation speed for homogenization of oil, and a cold finger which is made of two coaxial stainless steel tubes. An outlet for the cooling water bath (model LAUDA PROLINE P18 with $\pm 0.01^{\circ} \mathrm{C}$ precision, 8 pressure pump levels and operating temperature from -30 to $300{ }^{\circ} \mathrm{C}$ ) is placed on top of the internal stainless steel tube, with another exit a centimeter above the bottom of the external tube. The cooling water exits in the opposite direction of the inlet water from the top of external tube and is returned to the cold water bath. The external and internal tubes have a length of $25 \mathrm{~cm}$ and $20 \mathrm{~cm}$, and a diameter of $17 \mathrm{~mm}$ and $6.4 \mathrm{~mm}$, respectively. In order to decrease thermal resistance to heat transfer, thickness of external tube was reduced to $1 \mathrm{~mm}$. The water from circulating hot water bath (manufactured by Padideh Nogen Pars model CPN70 with $6 \mathrm{~L}$ bath volume, $\pm 0.5{ }^{\circ} \mathrm{C}$ precision and operating temperature from ambient to $100{ }^{\circ} \mathrm{C}$ ) flows through a copper coil to set the oil temperature. 


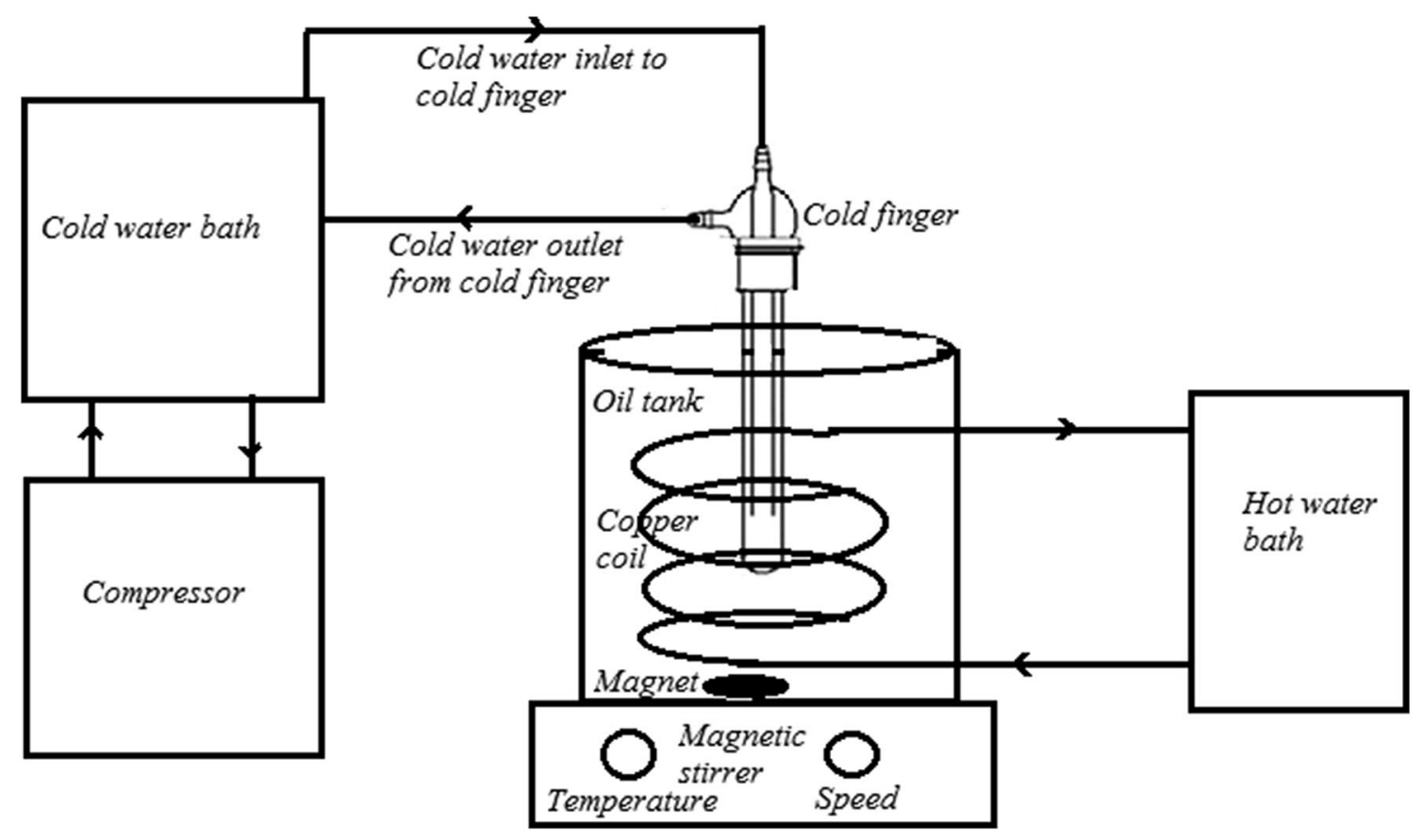

Fig. 1 Schematic of laboratory cold finger setup

\section{Sample preparation}

Before preparing mixtures for wax appearance temperature measurement, the crude oil samples were heated to $80{ }^{\circ} \mathrm{C}$ for $2 \mathrm{~h}$ till all the paraffin crystals completely dissolved in oil. Then, this mixture was gently cooled down from 80 to $30{ }^{\circ} \mathrm{C}$ (about $5{ }^{\circ} \mathrm{C}$ above the WAT). Various mixtures of EVA-toluene-chemical solvent with 40,30 , and $30 \mathrm{wt} \%$ were, respectively, prepared and different dosages of these mixtures including 600,800, and $1200 \mathrm{ppm}$ were added in crude oil to prepared different samples. These solutions were homogenized using a WiseTis HG-15D mixer for $0.5 \mathrm{~h}$ with $15,000 \mathrm{rpm}$ stirring rate.

For the cold finger experiments, different mixtures of kerosene-paraffin wax $(8 \mathrm{wt} \%)$ were prepared and heated same as above method. Proper dispersion of water particles and additives in the oil mixture is one of the main concerns of wax deposition experiments; therefore, a mixer with $15,000 \mathrm{rpm}$ speed was used to homogenize the water-oil mixtures. Then, the oil samples were gradually cooled to $30{ }^{\circ} \mathrm{C}$ and the cooling water pump was started to flow water into cold finger apparatus. When the temperature of cold surface was as desired-i.e., nine cold surface test temperature including $0,4,10,25,36$, $39,42,45$ and $50{ }^{\circ} \mathrm{C}$-it was gently placed in the center of the oil reservoir.

\section{Experiments}

In this work, the effect of different parameters on the amount of wax deposition was investigated by cold finger setup and the effect of various chemical inhibitors on WAT was studied by a viscometer. Different experimental tests were conducted in the cold finger setup to examine the effects of the temperature difference between a waxy oil mixture and cold surface, deposition time, water cut, stirring rate, and chemical inhibitors on the amount of deposited wax. During each experiment, one of the parameters was changed and the rest remained constant. Wax concentration of the oil mixture was $8 \mathrm{wt} \%$ and was kept constant in all the experiments. For investigating the oil temperature effects, temperature of oil mixture was tested at four temperature levels including $30,40,46$ and $50{ }^{\circ} \mathrm{C}$ while the cold surface temperature was maintained at $4{ }^{\circ} \mathrm{C}$. Operating condition of this test was two different stirring rates of 240 and $840 \mathrm{rpm}$ at $2 \mathrm{~h}$. For studying of the cold surface temperature effects on amount of deposit with oil temperature of $40{ }^{\circ} \mathrm{C}$, its temperature was tested at 0,4 , $10,25,36,39,42,45$ and $50{ }^{\circ} \mathrm{C}$ while stirring rate was $240 \mathrm{rpm}$ and deposition time was $2 \mathrm{~h}$. At oil temperature of $40{ }^{\circ} \mathrm{C}$ and cold surface temperature of $4{ }^{\circ} \mathrm{C}$, the effect of agitation speed on amount of wax deposition within $2 \mathrm{~h}$ was investigated at six levels including $0,240,480,840$, 1080 , and $1300 \mathrm{rpm}$. To investigate the effect of water cut 
on the amount of deposition, five levels of water cut were used including $0,5,10,15$, and $20 \mathrm{wt} \%$. Also, deposition time was $2 \mathrm{~h}$, stirring rate was set to $1080 \mathrm{rpm}$, and oil and cold surface temperatures were kept constant at 40 and $4{ }^{\circ} \mathrm{C}$, respectively. In addition, effect of chemical inhibitors including DSO, acetone, p-xylene, EVA copolymer, MDEA, and methanol with $800 \mathrm{ppm}$ concentrations, $240 \mathrm{rpm}$ stirring speed and over $2 \mathrm{~h}$ was examined on wax deposition. Also, DSO was used in three other concentrations of 2, 3.5, and $5 \mathrm{wt} \%$. In addition, $800 \mathrm{ppm}$ of EVA-toluene mixture with $50 \mathrm{wt} \%$ EVA was also tested in four different agitation speeds including $0,240,840$, and $1080 \mathrm{rpm}$ to examine the effect of a combination of the inhibitor and stirring rate at oil temperature of $40{ }^{\circ} \mathrm{C}$ and $4{ }^{\circ} \mathrm{C}$ cold surface temperature. Impact of deposition time on the amount of deposit was also tested at different deposition times, two different stirring rate of 240 and $840 \mathrm{rpm}$, and two temperature gradients. Cold surface temperature was kept constant at $4{ }^{\circ} \mathrm{C}$ while oil temperature changed between 32 and $40{ }^{\circ} \mathrm{C}$. Each prepared sample was used only for one test to avoid any significant change in composition of the waxy mixtures while conducting the various experiments. At the end of each experiment, deposited wax was scrapped from a cold finger and weighed. Surface area (surface of cylindrical tube) of the deposit was calculated and the amount of deposit per surface area was determined.

In another part of this study, to investigate the effect of chemical inhibitors on the WAT, two methods of viscometer and DSC were employed. Three different dosages $(600,800$, and $1200 \mathrm{ppm})$ of chemical inhibitors including DSO, EVA-toluene-p-xylene, EVA-toluene-chloroform, EVA-toluene-DSO, and EVA-toluene-acetone were separately added to crude oil. Dynamic viscosity was measured by the SVM 3000 Anton Paar viscometer according to ASTM D7042. This viscometer is able to operate at temperature range from -56 to $105{ }^{\circ} \mathrm{C}$ with thermostat accuracy of $0.005^{\circ} \mathrm{C}$. For measuring the viscosity, prepared oil mixtures were cooled from 80 to $45^{\circ} \mathrm{C}$ with a cooling rate of $1{ }^{\circ} \mathrm{C} \mathrm{min}{ }^{-1}$. When the oil temperature reached $45^{\circ} \mathrm{C}, 2.5 \mathrm{ml}$ of homogenized mixture was injected into viscometer and the sample temperature was decreased to $0{ }^{\circ} \mathrm{C}$ at a cooling rate of $1{ }^{\circ} \mathrm{C} \mathrm{min}^{-1}$. The onset temperature of wax precipitation was determined by semi-log plotting of the dynamic viscosity versus the inverse of absolute temperature. WAT was the point wherein there was a sudden increase in oil viscosity as the temperature decreased. Also, Mettler Toledo DSC823e system was employed to measure WAT. Two hundred microliters of oil samples was injected into DSC and then heated from 25 to $80{ }^{\circ} \mathrm{C}$ with $3{ }^{\circ} \mathrm{C} \mathrm{min}^{-1}$ to completely dissolve the precipitated wax crystals. Subsequently, sample was cooled down from 80 to $-10{ }^{\circ} \mathrm{C}$ with a cooling rate of $3{ }^{\circ} \mathrm{C} \mathrm{min}^{-1}$. Wax deposition is an exothermic process and enthalpy of oil sample is reduced through the deposition phenomenon. In the enthalpy changes versus temperature plot, the point on the plot where the slope suddenly changes is the onset of wax formation.

\section{Results and discussion}

The effect of chemical inhibitors on the WAT and temperature gradient, deposition time, stirring speed, and water cut on the amount of paraffin deposition were all considered as part of this study. The results of the wax deposition experiments from the single-phase and two-phase flows in a cold finger setup and viscometer are described in the following section.

\section{Effect of temperature gradient on wax deposition}

Several experiments were conducted to investigate changes of wax deposition with temperature difference. In some experiments, the oil temperature was kept constant $\left(40{ }^{\circ} \mathrm{C}\right)$ and the cold surface temperature was changed $(0,4,10,25$, $36,39,42,45$ and $50{ }^{\circ} \mathrm{C}$ ), and in others, the cold surface temperature was kept constant $\left(4^{\circ} \mathrm{C}\right)$ and the oil temperature was varied $\left(30,40,46\right.$ and $\left.50^{\circ} \mathrm{C}\right)$. Each test was repeated 2 times with $0.85 \% \mathrm{AAD}$. It was revealed that the cold surface temperature has a major effect on the mass of wax deposition. As mentioned earlier, solid wax crystals are formed when the oil temperature is below the WAT. In addition, temperature gradient between oil sample and cold medium is essential for wax deposition. Figure 2 shows the trend of wax deposition mass versus cold surface temperature at constant oil temperature $\left(40{ }^{\circ} \mathrm{C}\right)$ over $2 \mathrm{~h}$ and $240 \mathrm{rpm}$. Results present that deposition thickness decreases with increasing cold surface temperature at a constant oil temperature. The concentration gradient near cold surface increased with increasing of temperature difference between oil sample and pipe surface. Consequently, the wax deposition mass increased according to molecular diffusion law. The wax crystals did not deposit when the cold surface temperature was higher than the WAT. As shown in Fig. 2, wax deposition does not form when oil and cold surface temperatures are above the wax formation temperature $\left(38^{\circ} \mathrm{C}\right)$.

Figure 3 shows variation of deposition mass with increasing oil temperature at constant cold surface temperature $\left(4^{\circ} \mathrm{C}\right)$. According to this figure, wax deposition decreases with increase in oil temperature at a constant cold surface temperature. Increasing temperature difference at a constant cold surface temperature is equivalent to addition of more heat to oil. The paraffin solubility increases with increasing oil temperature; therefore, temperature of oil sample should be much higher than its wax formation temperature and consequently deposition mass

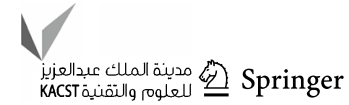




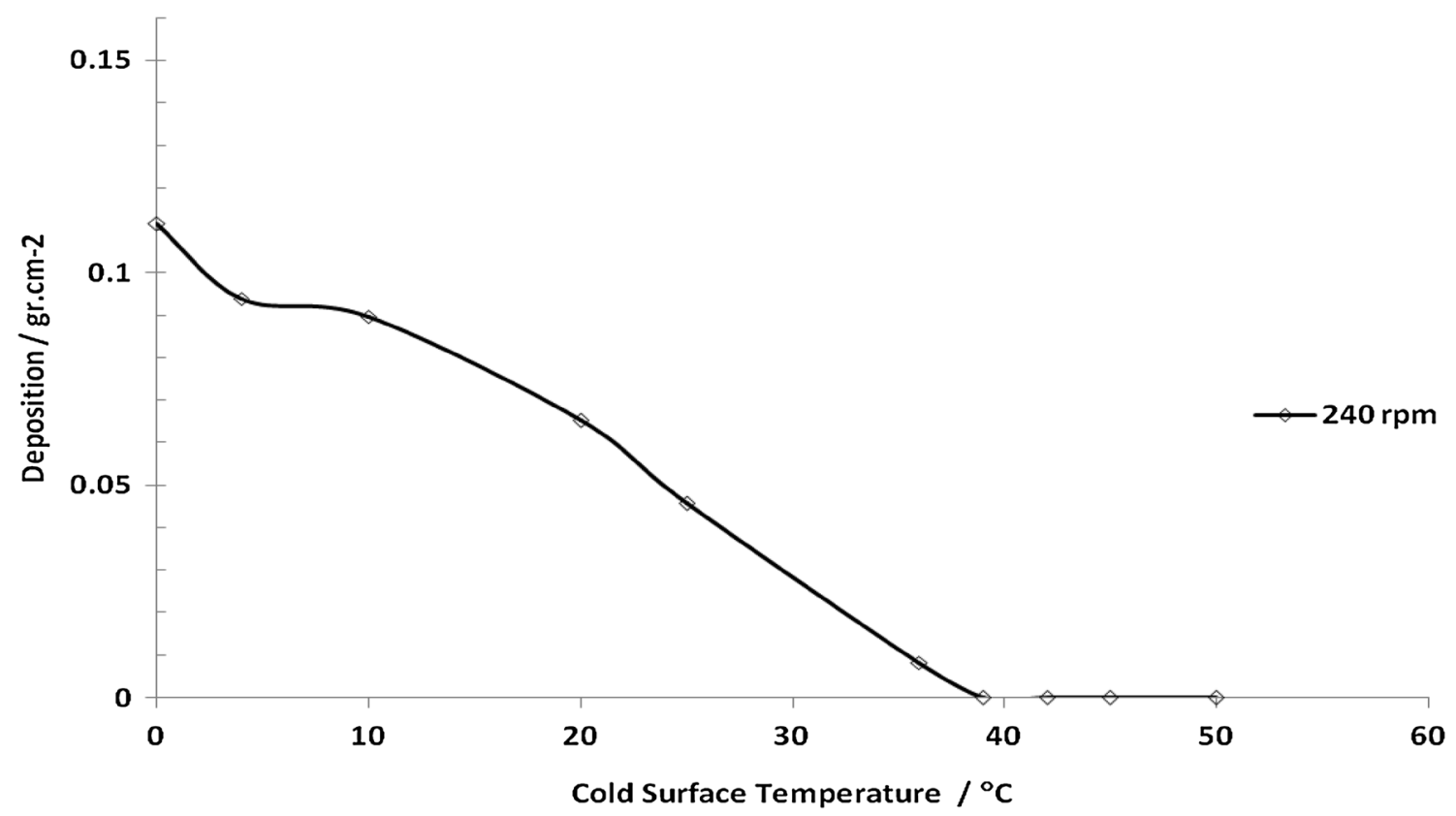

Fig. 2 Variation of wax deposition with cold surface temperature at constant oil temperature

Fig. 3 Variation of deposition mass with increasing oil temperature at constant cold surface temperature

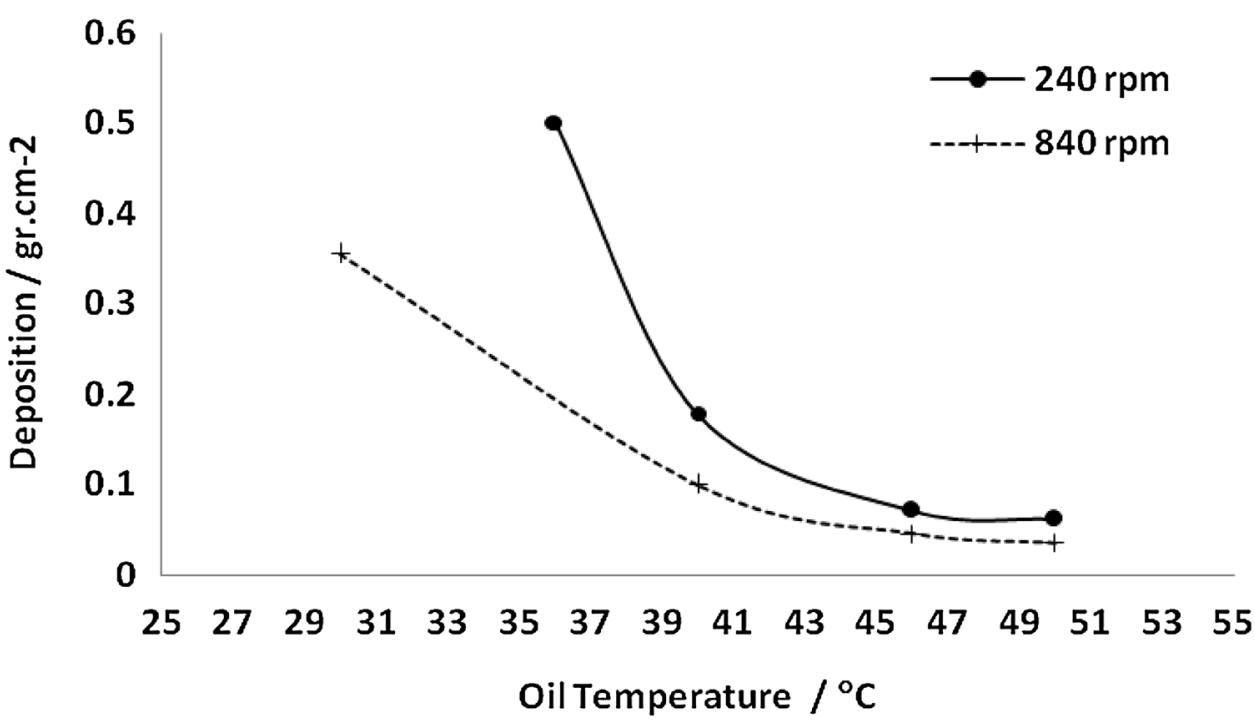

decreases. Figure 3 also shows that the deposition mass at higher stirring rates was lower than deposition at lower rates at the same temperature difference. It was observed that wax deposition reduced to more than $44 \%$ when the stirring rate increased from 240 to $840 \mathrm{rpm}$ at a temperature difference of $36{ }^{\circ} \mathrm{C}$. Results of this work are similar to that reported by Jennings and Weispfennig [12], Kelechukwu et al. [14], Bidmus and Malhotra [2], and Theyab and Diaz [26] studies.

\section{Effect of deposition time on wax deposition}

Wax deposition is proportional to time and changes along with it. Figure 4 presents the mass changes of wax deposition over time for two different temperature gradients and two stirring rates. This figure shows that wax deposition mass initially increased at a fast rate, but then its rate reduced. The reduction in the deposition mass over time can be due to formation of an isolating layer on cold surface and also 
Fig. 4 Variation of wax deposition mass with increasing time

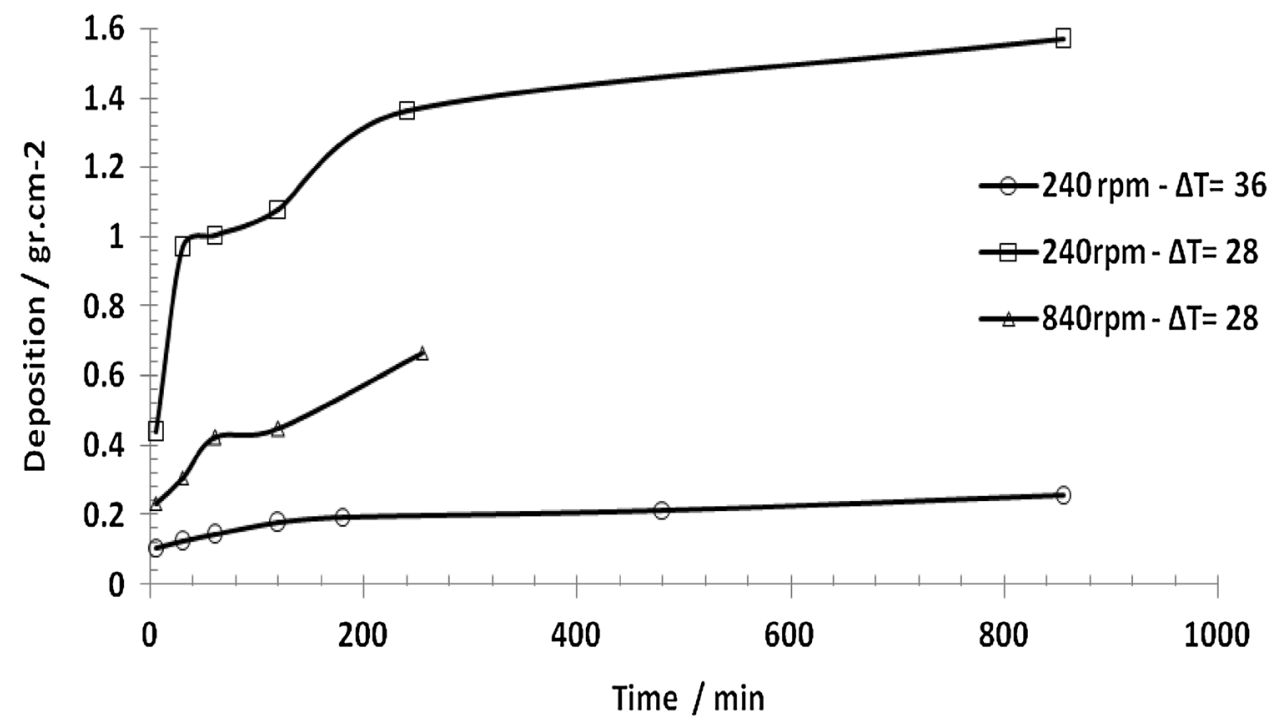

because of decreasing wax content available for deposition. Over time, the increase in the deposition thickness results in thermal resistance, which then also leads to a reduction in the heat transfer between oil and cold surface. Therefore, oil temperature increases gradually, leading to an increase in wax crystals solubility and consequently reducing the wax deposition. Also, cold finger setup is a closed system and no excess oil is introduced during tests. As paraffin deposition increases over time, the wax content of oil sample decreases and deposition does not change significantly after a certain time. Experiments were conducted at different time durations of 5, 30, 60, 120, 180, 480, and $855 \mathrm{~min}$. The stirring rate was set at 240 and $840 \mathrm{rpm}$, oil temperature changed in two levels of 40 and $32{ }^{\circ} \mathrm{C}$, and cold surface temperature was set at $4{ }^{\circ} \mathrm{C}$. Each test was performed 2 times with $1 \%$ AAD. Results show that more than $49.5 \%$ of wax deposition was formed in a short time that was less than $5 \mathrm{~min}$. About $67 \%$ of the wax crystals were deposited in the first hour of deposition process. This shows that wax deposition is a fast process initially that decreases subsequently over time. This figure shows that at similar times and $28{ }^{\circ} \mathrm{C}$ temperature gradient, deposition mass decreased between 46 and $68 \%$ by increasing stirring rate from 240 to $840 \mathrm{rpm}$. Also, it was observed that wax deposition decreased between 75 and $87 \%$ by increasing temperature gradient from 28 to $36^{\circ} \mathrm{C}$ at same time and $240 \mathrm{rpm}$ stirring rate.

\section{Effect of stirring speed on wax deposition}

To study the effect of turbulence on wax deposition, experiments were carried out at same operating conditions including $2 \mathrm{~h}$ deposition time, $8 \mathrm{wt} \%$ wax concentration, oil temperature of $40^{\circ} \mathrm{C}$, and cold surface temperature of $4{ }^{\circ} \mathrm{C}$. No chemical inhibitor was added, and there were trace amounts of water content in oil samples. The mixing rates of 0,240 ,
480, 840, 1080, and $1300 \mathrm{rpm}$ were examined. Each test was repeated twice. The Reynolds $(R e)$ number based on the rod length is defined as:

$\operatorname{Re}=\frac{\rho \varphi L^{2}}{\mu}$.

The dimensionless number of Nusselt $(\mathrm{Nu})$ is used to study convective heat transfer, defined as the ratio of convective to conductive heat transfer across the boundary. For laminar flow in the pipeline it is defined as follows:

$N u_{D}=\frac{h D}{k}=0.027 \operatorname{Re}^{4 / 5} \operatorname{Pr}$,

where $\mu / \mathrm{Pa} \mathrm{s}$ is the dynamic viscosity and $\varphi / \mathrm{rev} \mathrm{s}^{-1}$ is the stirring rate, $\mathrm{L} / \mathrm{m}$ is length of the stirrer rod, $\mathrm{D} / \mathrm{m}$ is diameter of oil tank, $\mathrm{k} / \mathrm{W} \mathrm{m}{ }^{-1} \mathrm{~K}^{-1}$ is thermal conductivity of waxy oil, and $\mathrm{h} / \mathrm{W} \mathrm{m}^{-2} \mathrm{~K}^{-1}$ is convective heat transfer coefficient. Also, Prandtl (Pr) number, defined as the ratio of momentum diffusivity to thermal diffusivity was calculated for 8 wt\% waxy oil and found approximately as 469.3. Different Reynolds numbers from 0 to 1071 were tested. This range corresponds to stirring rates from 0 to $22 \mathrm{rev} \mathrm{s}^{-1}$. Flows with Reynolds number less than the critical value of 1000 fall into the laminar regime. Therefore, all tests were carried out in the laminar flow regime near the transient regime. Figure 5 shows trends of Reynolds and Nusselt numbers with stirring rate at $40{ }^{\circ} \mathrm{C}$ oil and $4{ }^{\circ} \mathrm{C}$ cold surface temperatures.

It is observed that by increasing the stirring rate, Nusselt numbers increased at faster rate at the beginning, but its growth increased with moderate slope at higher turbulences. Figure 6 shows trend of wax deposition mass versus the mixing rate.

It was observed that deposition mass decreased gradually with increasing stirring rate. In Fig. 6, the highest wax

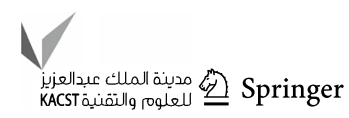


Fig. 5 Variation of Reynolds and Nusselt numbers with stirring rate
Fig. 6 Trend of wax deposition mass versus stirring rate at constant temperature difference of $36{ }^{\circ} \mathrm{C}$ and $2 \mathrm{~h}$
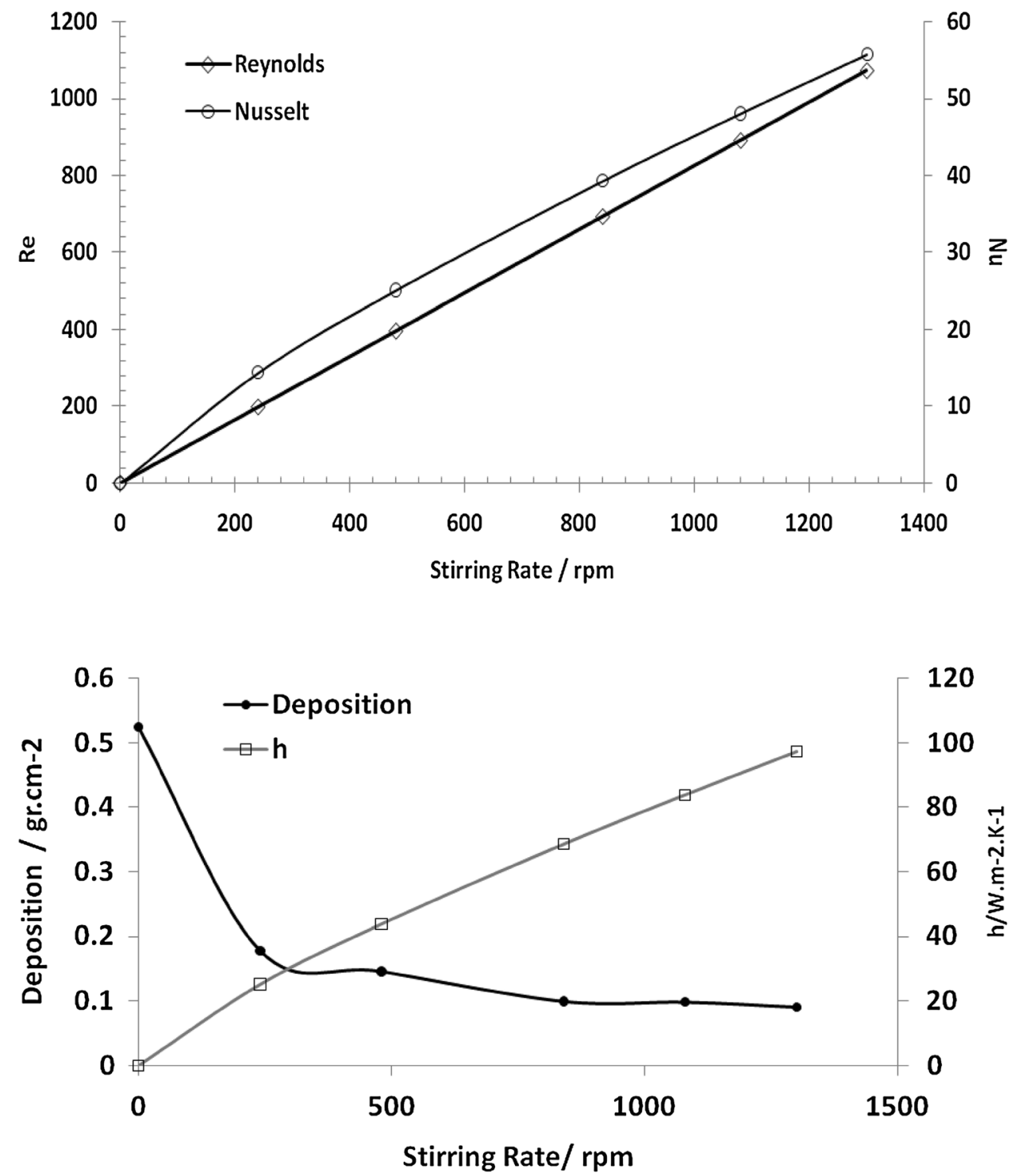

was deposited at $0 \mathrm{rpm}$ and the least amount of deposition was formed at $1300 \mathrm{rpm}$. Reduction of wax deposition mass with increasing mixing rate is a consequence of three important reasons including sloughing phenomenon, counter diffusion of wax molecules from the waxy sample into the wax layer and oil molecules from wax layer to the waxy sample, and the changes in thermal resistance. Convective heat transfer coefficient of the bulk oil increases with increasing mixing rate; therefore, the convective thermal resistance $\left(R_{\mathrm{o}}\right)$ reduces. For an experiment with a constant temperature gradient, reduction of convective thermal resistance leads to increase in the conductivity resistance $\left(R_{\mathrm{d}}\right)$ of the deposition layer. At a constant temperature difference and thermal flux, decreasing the convective resistance leads to increasing of the deposition resistance. The convective heat transfer coefficient increased from 0 to $124 \mathrm{~W} \mathrm{~m}^{-2} \mathrm{~K}^{-1}$ by increasing stirring rate from 0 to $1300 \mathrm{rpm}$. Results show that wax deposition did not change significantly at convective heat transfer coefficient above the $56 \mathrm{~W} \mathrm{~m}^{-2} \mathrm{~K}^{-1}$.

With increasing stirring rate, the amount of heavy and light molecular weight components in the deposition layer increase and decrease, respectively. Diffusion of the light components into oil mixture leads to reducing the amount of trapped oil and cavities inside the deposition layer and, consequently, wax deposition compacts and its thickness is decreased. The drag force increases with increasing stirring rate. Application of shear stress on the deposit surface leads to separation of the deposition layer from cold surface (sloughing) and returns to the bulk oil. Results of this study are consistent with studies of Theyab and Diaz [26], and Brown et al. [3]. 


\section{Effect of inhibitors on wax deposition}

The ability of chemical inhibitors to affect WAT as well as pour point temperature reduction of waxy oil mixtures are usually used for determining their efficiency. Generally, performance of inhibitors for WAT reduction is a strong function of their concentration. Chemical inhibitors including pure DSO, EVA-toluene-p-xylene, EVA-toluene-chloroform, EVA-toluene-DSO, and EVA-toluene-acetone with 40-30-30 wt\% were used for experiments. Each inhibitor was added to crude oil at different concentrations of 600 , 800 and 1200 ppm and WAT was measured. The WAT of original crude oil, without inhibitor, was measured by using Anton Paar SVM 3000 viscometer about $25.5{ }^{\circ} \mathrm{C}$. Table 1 summarizes measured WAT determined from viscosity data. Each test was performed for 2 times with $1.2 \%$ average absolute deviation (AAD) according to Eq. (3). Results suggest that WAT decreased with increasing inhibitor concentration. Furthermore, the greatest effect of inhibitor concentration for the WAT reduction occurred at $1200 \mathrm{ppm}$ for all samples, but this concentration is not significant if compared to $800 \mathrm{ppm}$. These results are similar to the Ridzuan et al. [22] study in which copolymers reduced the cloud point of a waxy oil:

$\mathrm{AAD}=\frac{\left|\operatorname{Exp}_{1}-\operatorname{Exp}_{2}\right|}{\operatorname{Exp}_{1}}$,

where $\operatorname{Exp}_{1}$ and $\operatorname{Exp}_{2}$ are experimental data measured in 1 and 2 times.

Table 1 presents that with increasing concentration of mixture from 600 to $1200 \mathrm{ppm}$ in a mixture of acetone-toluene-EVA, WAT reduced to about $11.94{ }^{\circ} \mathrm{C}$, $12.08{ }^{\circ} \mathrm{C}$, and $12.35{ }^{\circ} \mathrm{C}$ if compared to the original sample without an inhibitor. Results also suggest that WAT of p-xylene-toluene-EVA solution was reduced to about $10.7,10.88$, and $11.94{ }^{\circ} \mathrm{C}$ for 600,800 , and $1200 \mathrm{ppm}$ of

Table 1 Effect of different inhibitors on WAT

\begin{tabular}{lllrr}
\hline Oil & Inhibitor & WAT $\left({ }^{\circ} \mathrm{C}\right)$ \\
\hline Crude oil & N/A & 25.50 & \\
& & $\begin{array}{l}\text { Inhibitor concentration } \\
(\mathrm{ppm})\end{array}$ \\
& & 600 & 800 & 1200 \\
& & 28.23 & 23.44 & 15.06 \\
& DSO & 13.56 & 13.42 & 13.15 \\
& Acetone-toluene-EVA & 14.62 & 13.56 \\
& p-Xylene-toluene-EVA & 14.80 & 8.73 & 8.56 \\
& Chloroform-toluene- & 16.29 & & \\
& EVA & & 18.61 & 18.2 \\
\hline & DSO-toluene-EVA & 19.29 & & \\
\hline
\end{tabular}

*N/A not available the inhibitor concentration, respectively. For the chloroform-toluene-EVA mixture these values were 9.21, 16.77, and $16.94{ }^{\circ} \mathrm{C}$, respectively. DSO is a by-product of gas refineries which decreased the WAT at 800 and $1200 \mathrm{ppm}$, but WAT increased with increasing $600 \mathrm{ppm}$ of DSO. The optimum concentration of the DSO for WAT reduction was found at $1200 \mathrm{ppm}$. Also DSO was added to EVA-toluene mixture and this mixture reduced the WAT to about 6.21, 6.89 , and $7.3{ }^{\circ} \mathrm{C}$ for 600,800 , and $1200 \mathrm{ppm}$ of inhibitor concentrations, respectively. Results indicate that pure DSO has better efficiency at $1200 \mathrm{ppm}$ compared to EVA-toluene-DSO, but its combination with EVA-toluene at lower concentrations improved its performance for WAT reduction.

Comparison of results shows that mixtures with $30 \mathrm{wt} \%$ $\mathrm{CH}$ and $30 \mathrm{wt} \%$ DSO as chemical solvents, respectively, have the maximum and the minimum effect on WAT reduction. The mixture of acetone-toluene-EVA was very effective in reducing cloud point at minimum dosage (600 ppm), and the WAT reduced significantly at $800 \mathrm{ppm}$ of inhibitor but did not further decrease at higher dosages. p-Xylene-toluene-EVA solution also reduced cloud point as concentration increased, but there were no significant differential effects between various inhibitor concentrations.

In other experiments, the effect of chemical inhibitors such as EVA copolymer, DSO, acetone, p-xylene, methanol, and MDEA on the wax deposition was investigated. All tests were performed within $2 \mathrm{~h}$, zero water cut, $40^{\circ} \mathrm{C}$ oil temperature, and $4{ }^{\circ} \mathrm{C}$ cold surface temperature conditions. Also, each test was performed 2 times with $0.75 \%$ AAD. Results show that wax deposition decreased to about $23.35 \%$ by adding $2 \mathrm{wt} \%$ of EVA-toluene mixture (50 wt $\%$ toluene) at a $240 \mathrm{rpm}$ mixing rate. The polymer modifiers change the structure of wax crystals and lead them to create a weak network that disappears easily with the oil flow. Figure 7 shows the wax deposition that was formed from oil with EVA-toluene mixture and without it. This figure indicates that the deposited wax from the waxy oil-EVA copolymer mixture has a weak structure and is easily interrupted under low shear stress; in the absence of inhibitor, wax deposition has a strong structure and its removal needs higher force.

Figure 8 shows the effect of different inhibitors on wax deposition at a constant temperature difference and $240 \mathrm{rpm}$. Results also indicate that addition of $2 \mathrm{wt} \%$ MDEA solvent leads to a higher wax deposition; therefore, it should not be used to solve wax deposition problems. Despite the fact that mixture with DSO as chemical solvent had the least WAT reduction compared to other examined solvents, experiments conducted on a waxy oil mixture with different concentrations of DSO indicated that this solvent was able to reduce the wax deposition substantially. Results show that an increase in DSO concentration has an enhanced effect on reducing the wax deposition. When a waxy oil mixture with 2 wt $\%$ of DSO was used, wax deposition reduced to

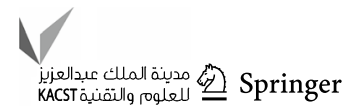


Fig. 7 Wax deposition at stirring rate of $240 \mathrm{rpm}$ and $2 \mathrm{~h}$. a With EVA-toluene inhibitor. b Without EVA-toluene inhibitor
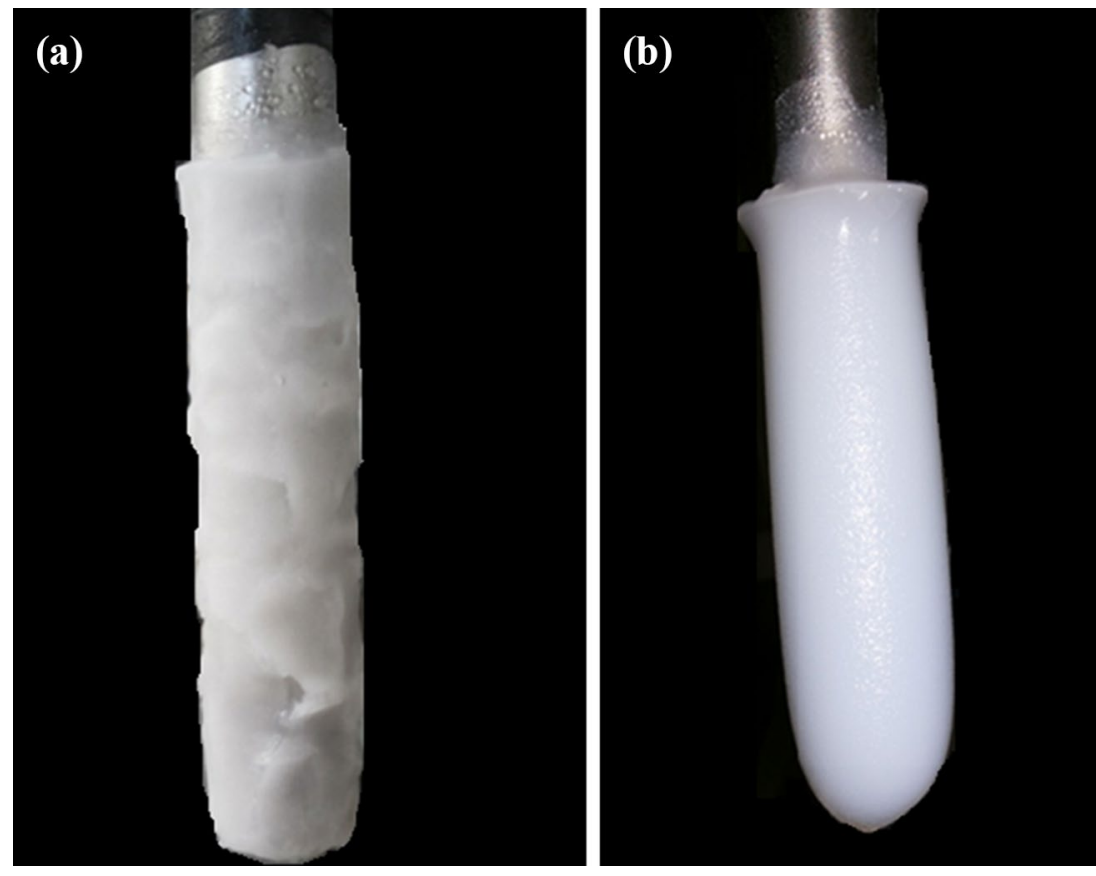

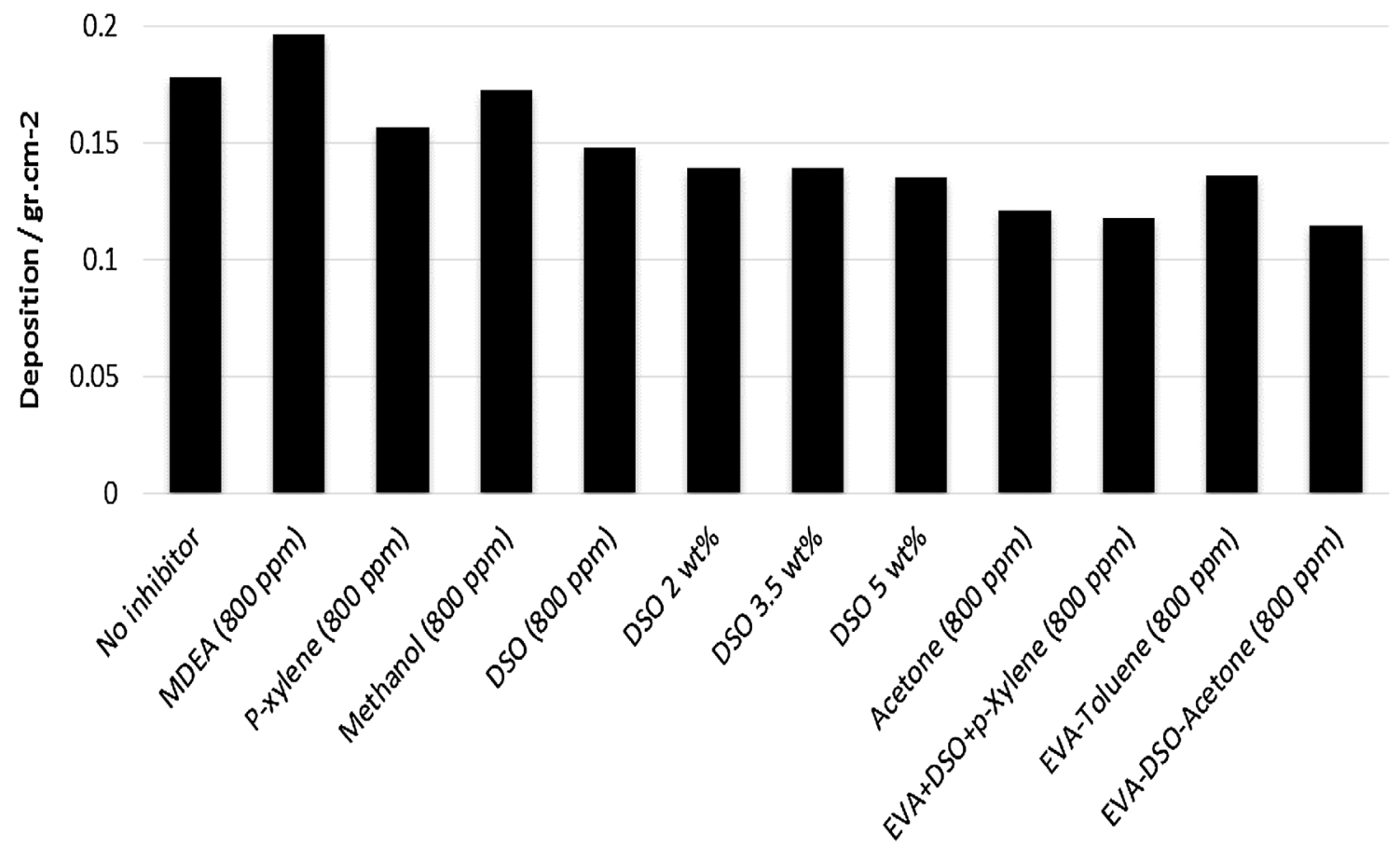

Fig. 8 Effect of different inhibitors on wax deposition at $240 \mathrm{rpm}$ stirring rate and $2 \mathrm{~h}$

more than $21.71 \%$, whereas it decreased to $23.8 \%$ at $5 \mathrm{wt} \%$ of DSO. In another test, methanol was used as a deposition reduction solvent, but it was observed that it had a negligible effect (about 5\%) on wax deposition. Results of experiments on the $\mathrm{p}$-xylene solvent present that although this solvent compared to other solvents had a lower effect on reducing the WAT, it still had a significant impact on decreasing the wax deposition (about $12.5 \%$ ). To study the effect of mixed inhibitors on wax deposition mass, experiments were conducted by adding $2 \mathrm{wt} \%$ of inhibitor containing EVA-DSO-p-xylene and EVA-DSO-acetone as solvents with $40-30-30 \mathrm{wt} \%$ and stirring rate of $240 \mathrm{rpm}$ 
at $2 \mathrm{~h}$. Results suggest that the reduction in deposited mass with mixture of inhibitors was greater than when each of these inhibitors was used alone. EVA-toluene $(50 \mathrm{wt} \%$ toluene), $2 \mathrm{wt} \% \mathrm{DSO}$, and $2 \mathrm{wt} \%$ p-xylene mixtures reduced deposition mass by approximately $23.33,21.71$, and $12.5 \%$, respectively. Acetone with $2 \mathrm{wt} \%$ was utilized as another chemical solvent for wax deposition. It was observed that acetone had a better control on the wax deposition compared to other inhibitors and was able to reduce it to $32.14 \%$. This solvent also had a good impact on WAT reduction of waxy oil mixtures. It was observed that using $2 \mathrm{wt} \%$ of EVA-DSO-acetone was reduced the deposit to $35.74 \%$. Also, wax deposition was decreased about $21.33 \%$ by adding $2 \mathrm{wt} \%$ of EVA-DSO-p-xylene with 40-30-30 wt\% to oil. Addition of solvents and crystal modifiers to waxy oil samples increases the solubility and modifies the structure of wax crystals, respectively. Thus, combining these two properties improves the solvent's efficiency and reduces the amount of wax deposition too.

\section{Effect of combination of inhibitors and stirring speed on wax deposition}

To study the effect of the simultaneous use of wax crystal modifiers and flow turbulence on a wax deposition mass, various experiments with different mixing rates including $0,240,840$, and $1080 \mathrm{rpm}$ at $2 \mathrm{~h}$ were done by addition of an EVA copolymer. As revealed in Fig. 9, wax deposition reduced significantly by combining the inhibitors and flow turbulence.

Results show that wax deposition reduced to more than $39.39 \%$ when the stirring rate of waxy oil-EVA mixture (800 ppm of mixture of EVA-toluene with $50 \mathrm{wt} \%$ EVA) was increased from 0 to $1080 \mathrm{rpm}$. In similar operating conditions, the flow turbulence when compared to inhibitors had a greater impact on reducing the wax deposition. For example, deposition mass decreased to $81 \%$ by increasing mixing rate to $1080 \mathrm{rpm}$ without any inhibitor, while with addition of $800 \mathrm{ppm}$ of inhibitor to oil sample at $840 \mathrm{rpm}$ it decreased to $80.82 \%$. Therefore, in terms of application, same deposition reduction can be achieved by using an effective inhibitor and average flow rate in the oil pipelines, which usually have a laminar flow. As mentioned above, the structure of wax crystals is modified by EVA to create a weak network. Combining the properties of chemical inhibitors with flow turbulence causes the deposit to break down by the least applied shear stress and, consequently, wax deposition reduces. Figure 10 shows the amount of wax deposited from waxy oil with EVA-toluene mixture at $240 \mathrm{rpm}$ and $1080 \mathrm{rpm}$.

\section{Effect of water cuts on wax deposition}

There have been discrepancies in the findings of studies that have investigated the effect of water cuts on wax deposition. Various experiments with different water cuts were performed at a $1080 \mathrm{rpm}$ stirring rate, $40{ }^{\circ} \mathrm{C}$ oil temperature, $4{ }^{\circ} \mathrm{C}$ cold surface temperature, without inhibitor, and at $2 \mathrm{~h}$ deposition time. Each test was repeated for 2 times with $1.3 \%$ AAD. Figure 11 shows the trend of deposition mass versus water cuts. As shown in this figure, wax deposition mass decreased with increasing water cuts. These results indicate that by increasing the water cut, wax deposition decreases initially to minimum value at a $5 \mathrm{wt} \%$ water cut and then increases gradually. The amount of deposition increased with increasing water cut, but its amount was

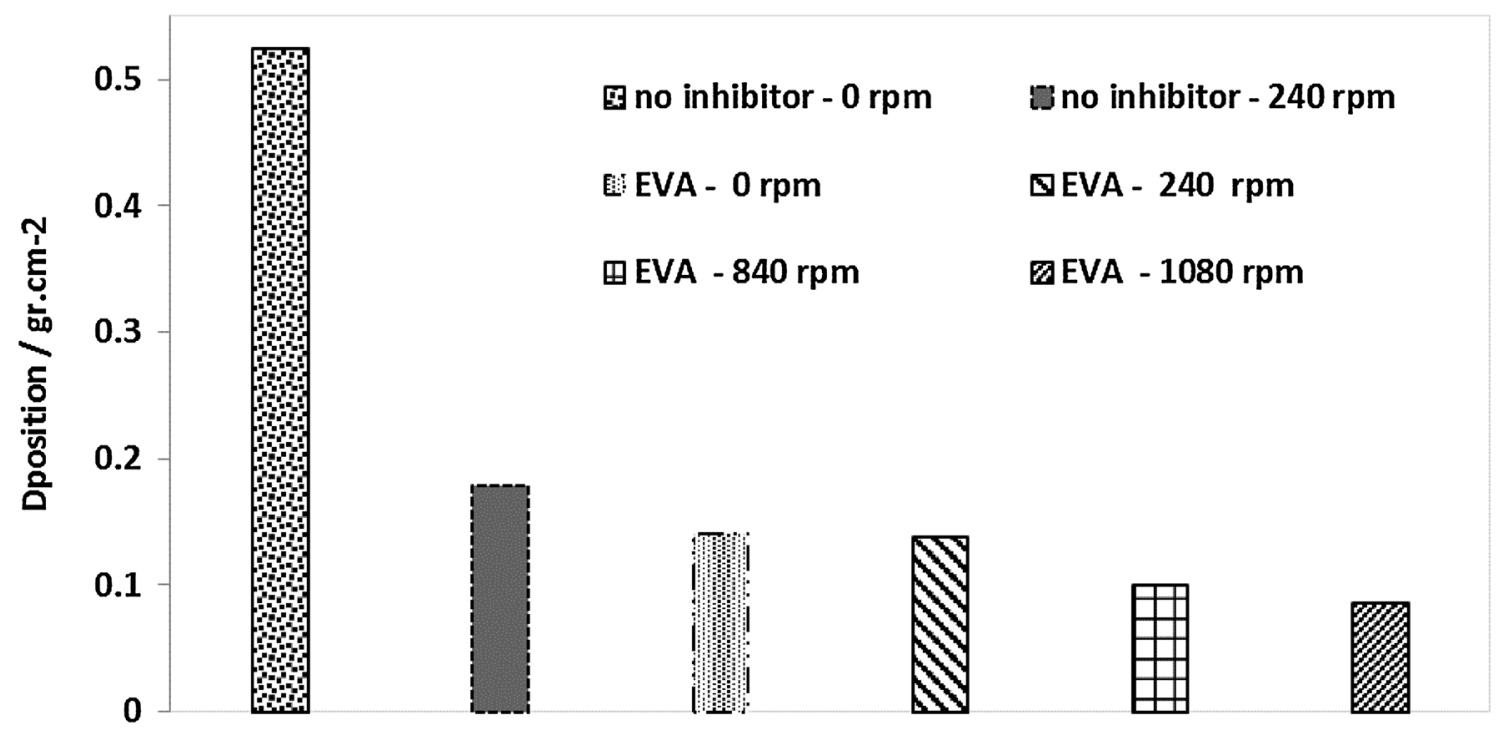

Fig. 9 Effect of combination of inhibitor and stirring rate on wax deposition at constant temperature difference and $2 \mathrm{~h}$ 


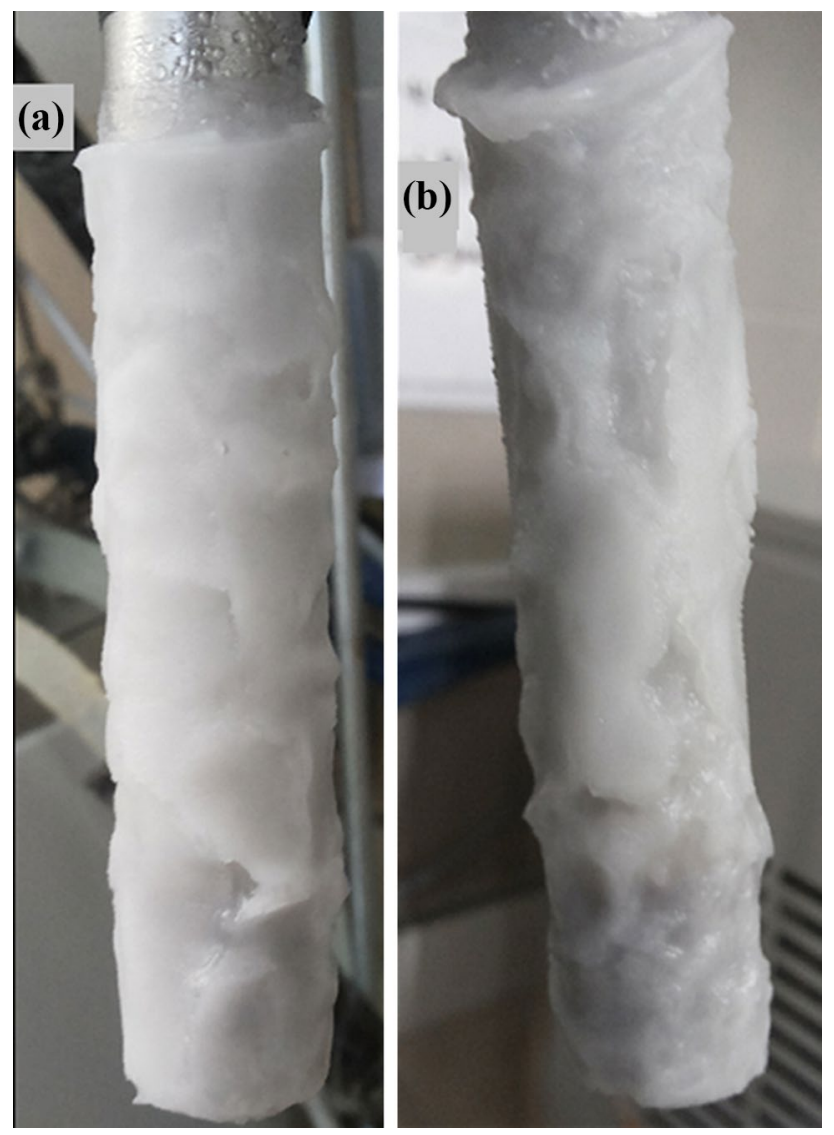

Fig. 10 Wax deposition on cold finger. a With EVA-toluene inhibitor and at $240 \mathrm{rpm}$. b With EVA-toluene inhibitor at $1080 \mathrm{rpm}$

less than the amount of wax that was formed from water to free oil mixture. Figure 11 indicates that in waxy oil mixture with $5 \mathrm{wt} \%$ water cut, wax deposition was reduced to $17.55 \%$ when compared to the water-free oil mixture, but it decreased to $15.30,13.26$, and $8.27 \%$ when water cut increased to 10,15 , and $20 \mathrm{wt} \%$, respectively.

These results are not similar to those obtained by Kasumu and Mehrotra [13] wherein they did not observe any changes in the deposition mass resulting from changes in the amount of water cuts. In spite of these reports, Zhang et al. [33] in studies regarding a flow loop showed that the effect of water cuts on wax deposition was different at different temperatures; however, wax deposition initially increased with an increase in the water cut but decreased after that. The deposited wax from two-phase water-waxy oil mixtures had a rough surface with high water content. It was also observed that this deposit had a lower hardness compared to one that was formed from the water-free waxy oil mixtures.

\section{Conclusion}

In this work, effect of different operating parameters and several inhibitors on wax deposition and WAT was studied. Cold finger setup was used for deposition mass and viscometer and DSC were utilized for WAT measurements. Results showed that mixture of EVA-toluene-chloroform with $40-30-30 \mathrm{wt} \%$ had best performance on WAT reduction while mixture of EVA-toluene-DSO with similar dosage had a minimum effect on it. Also, it was observed that WAT reduction increased by increasing inhibitor concentration, although $800 \mathrm{ppm}$ was obtained as optimum concentration. Effect of DSO on WAT and amount of wax deposition was studied for the first time. Pure DSO had a good effect at $1200 \mathrm{ppm}$ for WAT reduction, but its combination with EVA decreased its efficiency at high dosages. Keeping oil temperature WAT is the best and easiest way to prevent wax deposition. Deposition mass decreased by increasing oil temperature at a constant cold surface temperature. On the
Fig. 11 Effect of water cut on amount of wax deposition with stirring rate of $1080 \mathrm{rpm}, 40{ }^{\circ} \mathrm{C}$ oil temperature and $4{ }^{\circ} \mathrm{C}$ cold surface temperature at $2 \mathrm{~h}$

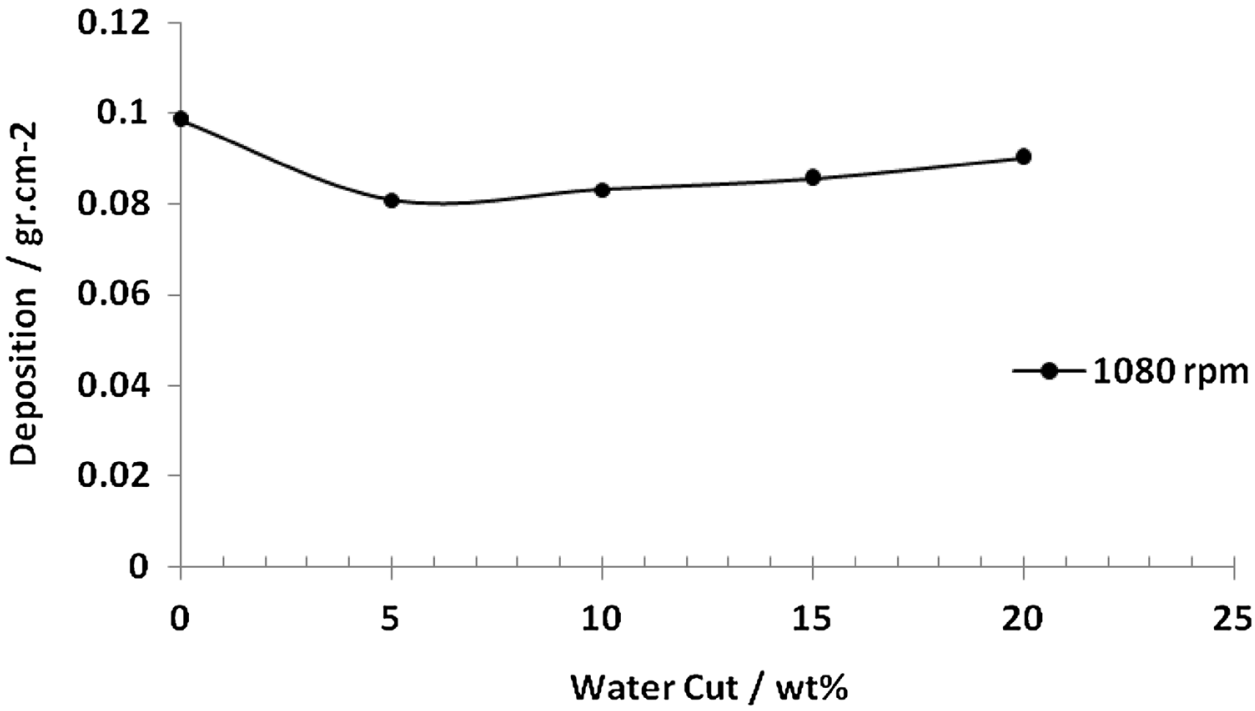


other side, it increased by decreasing cold surface temperature at constant oil temperature. Results show that high portion of wax is deposited at short times. Flow turbulence has a reverse effect on wax deposition and deposition decreased by increasing stirring rate. Also, it was found that wax deposition has a weak network when EVA is used and is easily interrupted under low shear stress. Acetone and p-xylene have a better control on amount of wax deposition compared to other chemical inhibitors, respectively. In addition, results showed that deposited wax from combination of chemical inhibitors were lower than when each of these inhibitors was used alone. Also, our finding indicates that simultaneous usage of wax crystal modifiers and flow turbulence reduced wax deposition significantly. At similar operating conditions, flow turbulence has a greater impact on reducing the wax deposition compared to inhibitors. Therefore, using a proper inhibitor and medium turbulence can prevent wax deposition. Finally, results of water cut experiments showed that wax deposition mass in two-phase system is lower than in a single-phase system, but increased with increasing water cut.

Open Access This article is distributed under the terms of the Creative Commons Attribution 4.0 International License (http://creativecommons.org/licenses/by/4.0/), which permits unrestricted use, distribution, and reproduction in any medium, provided you give appropriate credit to the original author(s) and the source, provide a link to the Creative Commons license, and indicate if changes were made.

\section{References}

1. Agrawal KM, Khan HU, Surianarayanan M, Joshi GC (1990) Wax deposition of Bombay high crude oil under flowing conditions. Fuel 69:794-796

2. Bidmus HO, Malhotra A (2009) Solids deposition during "Cold Flow" of wax-solvent mixtures in a flow-loop apparatus with heat transfer. Energy Fuels 23:3184-3194

3. Brown TS, Niesen VG, Erickson DD (1993) Measurement and prediction of the kinetics of paraffin deposition. Soc Pet Eng. https ://doi.org/10.2118/26548-ms

4. Burger ED, Perkins TK, Striegler JH (1981) Studies of wax deposition in the Trans Alaska pipeline. Soc Pet Eng. https://doi. org/10.2118/8788-pa

5. Chi Y, Daraboina N, Sarica C (2017) Effect of the flow field on the wax deposition and performance of wax inhibitors: cold finger and flow loop testing. Energy Fuels 31:4915-4924

6. Couto GH, Chen H, Dellecase E, Sarica C, Volk M (2006) An investigation of two-phase oil/water paraffin deposition. Offshore Technol Conf. https://doi.org/10.4043/17963-ms

7. Creek JL, Lund HJ, Brill JP, Volk M (1999) Wax deposition in single phase flow. Fluid Phase Equilib 158:801-811

8. Gao C (2003) Investigation of long term paraffin deposition behavior for South Pelto oil. MS Thesis, The University of Tulsa, Tulsa, Oklahoma

9. Hsu JJC, Brubaker JP (1995) Wax deposition measurement and scale-up modeling for waxy live crudes under turbulent flow conditions. Soc Pet Eng. https://doi.org/10.2118/29976-ms
10. Huang Z, Lee HS, Senra M, Fogler HS (2011) A fundamental model of wax deposition in subsea oil pipelines. AIChE J 57(11):2955-2964

11. Jafari Ansaroudi HR, Vafaie-Sefti M, Masoudi S, Jafari Behbahani T, Jafari H (2013) Study of the morphology of wax crystals in the presence of ethylene-co-vinyl acetate copolymer. Pet Sci Technol 31(6):643-651

12. Jennings DW, Weispfennig K (2005) Effects of shear and temperature on wax deposition: coldfinger investigation with a gulf of Mexico crude oil. Energy Fuels 19:1376-1386

13. Kasumu AS, Mehrotra AK (2015) Solids deposition from waxsolvent-water "Waxy" mixtures using a cold finger apparatus. Energy Fuels 29(2):501-511

14. Kelechukwu EM, Al Salim HSS, Yassin AAM (2010) Influencing factors governing paraffin wax deposition during crude production. Int J Phys Sci 5(15):2351-2362

15. Kudaibergenov SE, Didukh AG, Ibraeva ZE, Bimendina LA, Rullens F, Devillers M, Laschewsky A (2005) A regular, hydrophobically modified polyampholyte as novel pour point depressant. J Appl Polym Sci 98:2101-2108

16. Lashkarbolooki M, Esmaeilzadeh F, Mowla D (2011) Mitigation of wax deposition by wax-crystal modifier for Kermanshah crude oil. J Dispers Sci Technol 32(7):975-985

17. Lashkarbolooki M, Seyfaee A, Esmaeilzadeh F, Mowla D (2010) Experimental investigation of wax deposition in Kermanshah crude oil through a monitored flow loop apparatus. Energy Fuels 24:1234-1241

18. Lu Y, Huang Z, Hoffmann R, Amundsen L, Fogler HS (2012) Counterintuitive effects of the oil flow rate on wax deposition. Energy Fuels 26(7):4091-4097

19. Mansourpoor M, Azin R, Osfouri S, Izadpanah AA (2018) Effect of DSO, EVA, and $\mathrm{SiO} 2$ and clay nanohybrids on rheological properties of waxy oil mixtures. Mater Res Exp 5:095027

20. Matzain A (1996) Single phase liquid paraffin deposition modeling," MS Thesis, The University of Tulsa, Tulsa, Oklahoma

21. Panacharoensawad E, Sarica C (2013) Experimental study of single-phase and two-phase water-in-crude-oil dispersed flow wax deposition in a mini pilot-scale flow loop. Energy Fuels 27(9):5036-5053

22. Ridzuan N, Adam F, Yaacob Z (2016) Evaluation of the inhibitor selection on wax deposition for Malaysian crude oil. Pet Sci Technol 34(4):366-371

23. Senra MJ (2009) Assessing the role of polydispersity and cocrystallization on crystallizing n-alkanes in n-alkane solutions. University of Michigan, Ph.D. thesis

24. Singh P, Venkatesan R, Fogler H, Nagarajan N (2000) Formation and aging of incipient thin film wax-oil gels. AIChE J 46(5):1059-1074

25. Singhal HK, Sahai GC, Pundeer GS, Chandra K (1991) Designing and selecting wax crystal modifier for optimum field performance based on crude oil composition. Soc Pet Eng. https://doi. org/10.2118/22784-ms

26. Theyab MA, Diaz PA (2016) Experimental study on the effect of spiral flow on wax deposition volume. Soc Pet Eng. https://doi. org/10.2118/182936-ms

27. Towler BF, Jaripatke O, Mokhatab S (2011) Experimental investigations of the mitigation of paraffin wax deposition in crude oil using chemical additives. Pet Sci Technol 29:468-483

28. Venkatesan R (2004) The deposition and rheology of organic gels. PhD Thesis, Dept. of Chemical Engineering, University of Michigan

29. Wei B (2015) Recent advances on mitigating wax problem using polymeric wax crystal modifier. J Petrol Explor Prod Technol $5: 391-401$

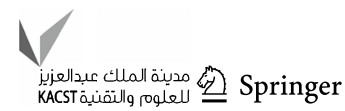


30. Weingarten JS, Euchner JA (1988) Methods for predicting wax precipitation and deposition. SPE Prod Eng 3(1):121-126 (SPE-15654-PA)

31. Yang F, Zhao Y, Sjöblom J, Li C, Paso KG (2015) Polymeric wax inhibitors and pour point depressants for waxy crude oils: a critical review. J Dispers Sci Technol 36(2):213-225

32. Zhang Y, Gong J, Ren Y, Wang P (2010) Effect of emulsion characteristics on wax deposition from water-in-waxy crude oil emulsions under static cooling conditions. Energy Fuels 24:1146-1155

33. Zhang Y, Gong J, Wu H (2010) An experimental study on wax deposition of water in waxy crude oil emulsions. Pet Sci Technol 28:1653-1664
34. Zhu T, Walker JA, Liang J (2008) Evaluation of wax deposition and its control during production of Alaska North Slope oils. Final Report, University of Alaska Fairbanks, Prepared for: United States Department of Energy, National Energy Technology Laboratory

Publisher's Note Springer Nature remains neutral with regard to jurisdictional claims in published maps and institutional affiliations. 